\title{
On the Classification of Multipackage Machines with Toothed Rotors ${ }^{1}$
}

\author{
A. Yu. Smirnov, Doctor of Science (Engineering), \\ professor in a Chair of Nizhnyi Tagil Technical University
}

DOI: $10.3103 / \mathrm{S} 1068371209110121$

I am forced to speak with regards to an article by Yu.V. Smirnov regarding terminology that he allows in his publications and is contrary to the prevailing terminology in the domestic school of electromechanics $[1,2]$.

In accordance with the prevalent classification and terminology, which completely reflects the essence of electromagnetic processes, only three categories of machines that have rotors with teeth and without windings can exist, including reluctance, inductor, and inductor-reluctance.

In reluctance machines, the conversion of energy takes place due to variations in the self-induction flux of the armature winding, but only in the case when the constant-voltage or current sources or single half-wave rectifiers are absent in the external electric circuits of these machines, which are connected with the armature winding. In inductor machines, the conversion of energy takes place due to the mutual induction flux of the armature and inductor fields, including the exciting field formed by the supply of the single multiple-phase winding of the armature with the nonreversible current.

Machines with numbers of teeth and poles that simultaneously meet the conditions of the conversion of energy in both the inductor and reluctance motors are related to inductor-reluctance machines. For this category, machines with insulated (in magnetic respect) phases are numbered in [2] (see Figs. 5-21 on p. 202). The shape of coils and magnetic cores in this case does not have significance.

It is only important that phase fluxes in machines of similar designs continue to be insulated from one another. This machine can be classified as an aggregate

\footnotetext{
${ }^{1}$ Remarks on the article by Yu. V. Smirnov "Three-Phase Electromagnetic AC Motors", Elektrotekhnika, 2009, no. 5, pp. 11-14.
}

of three (based on the number of phases) single-phase synchronous motors of the reluctance or inductor (depending on the nature of supply) type operating on a common shaft.

No electromagnetic ac motors are included in the classification of electrical machines!

In the same source, which was prepared by the talented Russian scientist and inventor, professor B.A. Ivobotenko, it is claimed that, in the step mode, which can be considered a transient mode of operating any synchronous machine, a three-phase motor with the complete absence of links is an extremely unsuccessful machine [2, pp. 331, 332].

This is exactly the case when uncertain classification and terminology results in ignoring the achievements of previous generations of scientists and inventors and force one to reinvent the wheel.

Other remarks on the article are given below:

(i). The term "magnetizing force" (MF) used by author is now anachronistic; instead, the term "magnetic driving force" (MDF) should of course be used.

(ii). The authors were surprised by problems in the development of the computation model of these machines. Numerical modeling by the finite element method allows one to not only check calculations of some variants of similar products on the fly, but also to reproduce operations that involve the electric drive.

\section{REFERENCES}

1. Ivanov-Smolenskii, A.V., Elektricheskie mashiny (Electric Machines), Moscow: Energiya, 1980, pp. 168-186.

2. Diskretnyi elektroprivod s shagovymi dvigatelyami (Discrete Electric Drive with Stepping Motors), Chilikin, M.G., Ed., Moscow: Energiya, 1971 